\title{
Incidence of HIV in Antenatal Women Attending a Tertiary Care Hospital in Hyderabad, Telangana, India
}

\author{
Farhana Aljabri $^{1}$, B. Satyanarayana ${ }^{2}$, R. Shyamala ${ }^{3 *}$ and K. S. Saraswathi ${ }^{1}$ \\ ${ }^{1}$ Department of Obstetrics \& Gynaecology, Shadan Institute of Medical Sciences \& P.G \\ Research Centre, Hyderabad, Telangana, India \\ ${ }^{2}$ Department of Physiology, Malla Reddy Medical College for Women, Hyderabad, \\ Telangana, India \\ ${ }^{3}$ Department of Microbiology, Malla Reddy Medical College for Women, Hyderabad, \\ Telangana, India \\ *Corresponding author
}

\section{A B S T R A C T}

\begin{tabular}{|l|}
\hline Ke y w o r d s \\
HIV, Pregnant women, \\
Mother to Child \\
transmission
\end{tabular}

\section{Introduction}

In 1983 Luc Montagnier and colleagues from Pasteur Institute, Paris isolated a Retrovirus from a West African patient with persistent generalised lymphadenopathy which is a manifestation of AIDS. (Ananth Narayan). In India the first HIV case was detected in 1986, and since then it has been reported from all states and union territories. According to National Aids Control Organization (NACO) the national adult HIV prevalence in India is $0.36 \%$ (Harsha Kumar).
This study was done to know the seroprevalence of Human Immunodeficiency virus in Pregnant women in a tertiary care hospital, Shadan Institute of Medical Sciences\& P.G Research Centre, Hyderabad from July 2007 to December 2015. First an ELISA test was conducted and after it is positive it is confirmed using two other tests. The study included 5781 patients, who were screened for HIV. Of these 5781 pregnant women, 15 were found to be positive for HIV $(0.20 \%)$. All pregnant women were followed up. First HIV counselling \& testing was done. Patient avails the Antenatal services and any concurrent infection was treated. Positive women were sent to ART Centre for free drugs. Proper ART/ARV prophylaxis was given and mother and baby were followed up. 
of information, education and communication on HIV/AIDS prevention (Laghave et al., 2015).

Six Indian states with high HIV and AIDS prevalence are Manipur (1.4\%), Andhra Pradesh (0.90\%), Mizoram (0.81\%), Nagaland $(0.78 \%)$, Karnataka $(0.63 \%)$ and Maharashtra $(0.55 \%)$. Prevalence of HIV infection among pregnant women in India is reducing. The prevalence of AIDS in India has declined in 2015 (0.26\%) as compared to 2001-2003 $(0.38 \%)$ (NACO, 2016).

In India women account for around one million out of 2.5 million estimated number of people living with HIV/AIDS. Their heightened vulnerability has both biological and socioeconomic reasons. Early marriage, violence and sexual abuse against women, illiteracy are the major socioeconomic reasons of their vulnerability to HIV infection. Their biological construct makes them more susceptible to HIV infection in any given heterosexual encounter. In 1992 India's National Aids Control Organisation was established by the ministry of Health and Family welfare with major support from World Bank.

Six Indian states are considered to have high HIV- AIDS prevalence (>1\%) Manipur, Nagaland, Andhra Pradesh, Tamil nadu, Karnataka and Maharashtra- as are 49 districts with in states.

HIV prevalence has been increasing among pregnant women in many regions with in the country.

HIV screening in antenatal women is important, because HIV can be transmitted from an infected mother to her child during pregnancy, labour and delivery, and through breast feeding. In the absence of breastfeeding most infections occur during labour and delivery. Reported transmission rates ranged from $13-32 \%$ in industrialised countries and from 25 to $48 \%$ in developing countries (Dabis et al., 2015).

A single dose of $200 \mathrm{mg}$ of nevirapine will be administered to the mother during the first stage of labour and single dose of $2 \mathrm{mg} / \mathrm{kg}$ body weight to the newborn with in 72 hours of birth is given, to prevent MTCT in developing countries (R.B Pollard et al.,).

\section{Materials and Methods}

This is a retrospective study from Shadan Institute of Medical Sciences \& P.G Research Centre. Hospital from July 2007 to December 2015. Blood samples were collected after pretest counselling and informed consent. The samples were tested for HIV antibodies as per NACO guidelines.

The first antibody test done was ELISA. If the initial result was positive, it was confirmed using two other supplemental tests. After HIV test results were known post-test counselling was done and the results were declared. Confidentiality of the data was maintained

\section{Results and Discussion}

5781 pregnant women attending the antenatal clinic at SIMS, during the period of July 2007 to December 2015 were tested for HIV. Out of these 15 women were tested positive accounting for $0.20 \%$.

In 1986, the first known case of HIV was diagnosed by Dr. Suniti Solomon, and her student, Dr. Selappan Nirmala amongst female sex workers in Chennai, Tamil Nadu. (Sternberg et al.,), (Pandey, et al.,)

The average HIV prevalence among women attending antenatal clinic in India is $0.48 \%$ as per NACO annual report 2010-2011. The 
figures vary widely between the various states of India- Andaman and Nicobar Islands $0.25 \%$, Andhra Pradesh $1 \%$.

In Pune, India the HIV infection rate in antenatal women was $2.2 \%$ in 2002-2003 and has declined to $0.73 \%$ in 2006 (Journal of Acquired ID)
Mother to child transmission is prevented by a four pronged strategy.

Primary prevention of HIV - By counselling the Antenatal women.

Prevent unintended pregnancies in the HIV positive women.

Pie Diagram.1 Showing the Incidence of HIV in pregnant women in a tertiary care hospital in Hyderabad

\section{Incidence of HIV in pregnant women in a tertiary care hospital in Hyderabad}

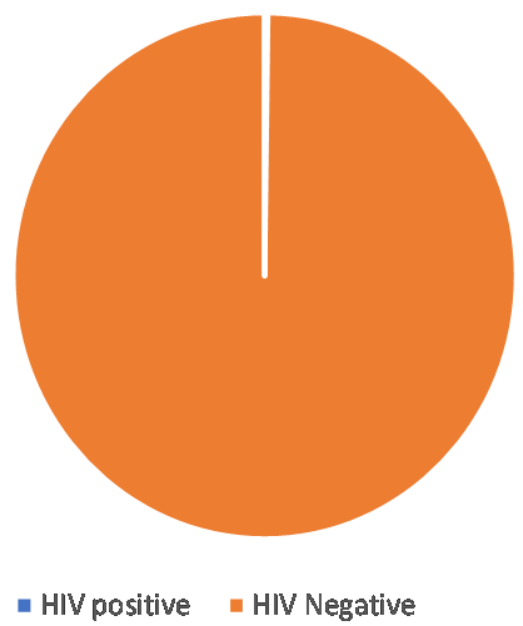

HIV positive and pregnant patient Prevention of Mother to child transmission.

HIV positive Mother \& Child - Care, support and treatment.

In India $90 \%$ of the reported cases of HIV are aged between 15 and 40 years and belong to low socioeconomic groups (Monica Malta et al.,).

Mother to child transmission of HIV infection during pregnancy, delivery or breast feeding is responsible for more than $90 \%$ of the HIV infection in children. Hence appropriate antenatal screening, interventions and preventive strategies during pregnancy, delivery and breastfeeding will bring down the mother to child transmission of HIV (K. M. Decock et al.,).

In our centre, all pregnant women are followed up. First HIV counselling \& testing is done. In positive women, patient should be sent to ART centre for free drugs.

Patient avails the antenatal services and any concurrent infection is treated. Proper ART/ ARV prophylaxis is given and mother \& baby are followed up. 


\section{References}

Ananthnarayan and Panicker's, a text book of Microbiology Universities Press 8th Edition pg-569.

Dabis, F., P. Mseliati, D. Dunn etal. AIDS 1993: 7(8): 1139-48

Decock, K.M., MG Fowler et al., JAMA 2000; 283(9): 1173-1180

Harsha Kumar. H.N., et al., Open Medicine 2009; 3(1): e 26-e30.
Monica Malta. et al., BMC Public Health, 2010, 10: 317.

NACO Annual report 2002-2004

Pandey, Geeta 2016-08-30. "The woman who discovered India's first HIV cases". BBC News. Retrieved 2016-12-08.

Pollard, R.B., et al., Clin Ther. 1998; 20; 1071-92

Sternberg, Steve 23 February 2005. HIV scars India USA Today.

\section{How to cite this article:}

Farhana Aljabri, B. Satyanarayana, R. Shyamala and Saraswathi K. S. 2018. Incidence of HIV in Antenatal Women Attending a Tertiary Care Hospital in Hyderabad, Telangana. Int.J.Curr.Microbiol.App.Sci. 7(06): 3064-3067. doi: https://doi.org/10.20546/ijcmas.2018.706.360 